\title{
Comparison of Angiographic Severity between Patients of Acute Myocardial Infarction \& Chronic Stable Angina Pectoris
}

\author{
MOHAMMAD SAFIUDDIN ${ }^{1}$, MIR JAMAL UDDIN ${ }^{5}$, SIRAJUL ISLAM ${ }^{1}$, SM AHSAN HABIB ${ }^{1}$, \\ MOHAMMAD ABU KAUSER ${ }^{2}$, MD.SAIF ULLAH KHAN ${ }^{6}$, MINHAJ RAHIM CHOUDHURY ${ }^{3}$, \\ FAZLUR RAHMAN ${ }^{1}$, SHAHNAJ BINTE SAFI ${ }^{4}$
}

\footnotetext{
${ }^{1}$ Department of Cardiology, Bangabandhu Sheikh Mujib Medical University, ${ }^{2}$ Department of Cardiology, NCCRF \& HD, ${ }^{3}$ Department of Rheumatology, Bangabandhu Sheikh Mujib Medical University, ${ }^{4}$ Bangladesh Medical College and Hospital, ${ }^{5}$ Department of Cardiology, National Institute of Cardiovascular Diseases, Dhaka, ${ }^{6}$ Department of Vascular Surgery, Bangabandhu Sheikh Mujib Medical University, Dhaka
}

Address for Correspondence : Dr. Mohammad Safiuddin, Associate Professor, Department of Cardiology, Bangabandhu Sheikh Mujib Medical University, Shahbagh, Dhaka-1000, Email: safiuddin1960@yahoo.com

\begin{abstract}
:
A prospective randomized cohort study was done in 100 patients and the study population consisted 50 patients with unheralded acute myocardial infarction and 50 with uncomplicated stable angina pectoris. The main objectives of the study were to compare the angiographic severity between the two clinical subsets of IHD. The study observed that regarding number of vessels diseased, the AMI group had $1.52 \pm 0.68$ compared with $2.37 \pm 0.85$ vessels for the angina group reflecting significantly higher diseased vessel in latter group $(P<0.001)$. In comparison with unheralded AMI, the stable angina group had greater number of stenoses $(4.16 \pm 1.9 \mathrm{vs}$ $2.14 \pm 1.5, P<0.001)$ and also greater number of occlusions $(0.80 \pm 0.65$ vs $0.44 \pm 0.31, P<0.001)$. Thus from the above data it is clear that single vessel disease is more frequent in AMI group and double-and tripple vessel diseases are more prevalent in angina group and fewer stenoses and discrete type of lesions in the former and more number of diseased vessels, more stenoses, and diffuse type of lesions in the latter.
\end{abstract}

Key word: Unheralded acute myocardial infarction; Uncomplicated Stable Angina Pectoris; Angiographic Severity.

\section{Introduction:}

Diagnostic selective coronary arteriography (CAG) is a safe and widely practiced procedure for the detection of coronary artey disease(CAD). First performed by Sones in 1959 , coronary arteriography has become one of the most widely performed and accurate test in cardiovascular medicine ${ }^{1}$. CAG findings showed various types of lesions in respect to their anatomy, severity of stenosis, extent of vessel involvment and morphology of the lesions in different types of ischaemic heart disease

With their initial myocardial infarction, more than $50 \%$ of all pateints have significant obsructive atherosclerosis in only one vessel.This fact emphasizes the potentials for secondary prevention ${ }^{2}$. Interestingly, lesions that occlude to produce acute syndromes are only moderately severe, typically 45 to 50 percent lumen diameter reduction ${ }^{3}$. A small number ( $<5$ percent) of patients with AMI are found to have normal coronary vessels ${ }^{4.5}$.
Among patients with chronic stable angina pectoris coronary angiography shows, approximately 25 percent of patients each have one-, two-, or three-vessel disease (i.e. $>70 \%$ luminal diameter narrowing); 5 to 10 percent have obstruction of the left main coronary artery; and in approximately 15 percent no critical obstruction is detectable $^{6}$.

There is a common belief that more extensive and severe coronary atherosclerosis would be present in patients with acute myocardial infarction than in those with chronic stable angina. Survivors of first acute MI, particularly in the younger group showed low prevalence of multivessel disease and residual infarct related stenoses were not necessarily severe ${ }^{7.8}$.

Methods and Materials:

This prospective study was carried out in the National Institute of Cardiovascular Diseases, Dhaka during the period from January'97 to March'98. A total of 100 cases, 
50 from each group as follows, were selected for analysis from 105 cases selected randomly from the patients admitted in my different units for CAG (Coronary angiogram). For better comparison equal number of patients were selected from both subsets of patients. Patients were selected from those who attended and got themselves admitted for CAG in different cardiolgy units. History and clinical findings including relevant investigation reports were scrutinized as per defined inclusion/exclusion criteria. CAG were performed by the expert cardiologists using the standard Judkin's procedure. Preliminary CAG reports from the unit concerned were collected. For more detailed information about CAG findings as mentioned in the proforma, each CAG films were reviewed and scrutinized carefully by two unbiased expert cardiologists and in doubtful cases the films were reviewed by an expert radiologist. When a consensus is not reached due to technical or visual error the case was discarded from the study. Coronary angiographic evaluation of both subsets were done on the basis of following angiographic criteria, which were also followed by the previous study groups ${ }^{9.10}$.

\section{Selection Criteria And Grouping of the Patients:}

The patients were grouped into two groups according to their diagnosis and selection criteria as follows:

Group -I : Unheralded acute myocardial infarction

Unheralded AMI means - AMI without any past history of IHD e.g. stable angina, unstable angina or $\mathrm{AMI}^{9.10}$

\section{Inclusion criteria forgroup-I:}

1) AMI is the first manifestation of IHD (prodrome of 4 wks chest pain permitted)

2) Diagnosis of Acute MI by presence of at least 2 of the followings:

- Characteristic chest pain

- Cardiac CK-MB enzymes > 2 times of normal upper limit

- ECG changes lasting $>48$ hrs .

3) CAG must be within 3 months of AMI ${ }^{9.10}$ Assumption is that CAG done within this time period may have better relation with the recent AMI and probably to avoid new atherosclerotic lesion after 3 months.

4) Men $£ 60$ yrs; Women $£ 65$ yrs
Exclusion criteria forGroup-I:

1) Past history of any form of ischaemic heart disease e.g: stable angina, unstable angina or myocardial infarction.

2) Men $>60$ yrs; Women $>65$ yrs.

3) CAG more than 3 months after acute MI.

Group -II : Uncomplicated stable angina pectoris

Uncomplicated Stable angina means - Stable angina pectoris without any history of acute coronary events e.g. Unstable angina or $\mathrm{AMI}^{9}$

Inclusion criteria for group-II:

1) At least 6 months history of typical stable angina.

2) Positive ETT test.

3) CAG must be done ${ }^{3} 6$ months after initial symptoms and there must not be any history of acute events upto \& including the time of CAG.

4) Men $£ 60$ yrs; Women $£ 65$ yrs.

Exclusion criteria for group-II:

1) Any history of acute coronary events (i.e-unstable angina or acute MI).

2) Any of the following ECG features:

- Q-wave

- $\mathrm{R} / \mathrm{S}>1$ in $\mathrm{V} 1$ or $\mathrm{V} 2$

- LBBB

- Pacemaker rhythm

3) Segmental akinesia or dyskinesia on LV graphy.

1) Men $>60$ yrs; Women $>65$ yrs

Angiographic Severity Criteria ${ }^{9.10}$

a)No. of vessels: No. of major epicardial vessels with 3 $70 \%$ stenoses (max-3)Lt. Main stenoses $350 \%=2$ vesselsb)No. of stenoses:Total no. of ${ }^{3} 50 \%$ narrowings on all the vessels of angiogramStenoses longer than twice the normal diameter $=2$ stenoses Max. 3 stenoses per segmentc)Occlusions:Number of occlusions / subtotal occlusions(with delayed or incomplete antegrade flow)

\section{Results:}

A total of 100 cases (mean age $48.98 \pm 8.37$ years) were selected for the study after fulfillment of inclusion and exclusion criteria . For better comparison equal number of patients were selected, 50(fifty) patiens in unheralded acute myocardial infarction (AMI)group (Group-I) and 
50(fifty) in stable angina pectoris(SAP) group (Group-II). Consecutive case collection were done and group -I reached the target figure first followed by group-II. A total of 5 (five) cases were discarded from the study due to failure to reach a consensus due to technical and /or visual error and subsequently those were replaced by 5 more cases.

Among the study population, 91 patients were male of which 49 in group-I and 42 in group-II and 9 patiens were female of which only 1 in group-I and remaining 8 were in group-II. Majority of AMI patients were younger whereas those of SAP (Stable angina pectoris) were relatively elderly. Age and sex distribution of the study population are shown in Table-I and Fig-I respectively.

\section{Table-I}

Age distribution of study population $(N=100)$

\begin{tabular}{lccc}
\hline Age(yrs) & $\begin{array}{c}\text { Gr-I } \\
\text { (AMI)-Number }\end{array}$ & $\begin{array}{c}\text { Gr-II } \\
\text { (SAP)-Number }\end{array}$ & $\begin{array}{c}\text { Total } \\
\text { No (\% ) }\end{array}$ \\
\hline$<31$ & 1 & 0 & $1(1)$ \\
$31-40$ & 16 & 4 & $20(20)$ \\
$41-50$ & 18 & 14 & $32(32)$ \\
$51-60$ & 11 & 20 & $31(31)$ \\
$61-65$ & 4 & 12 & $16(16)$ \\
\hline Total & 50 & 50 & $100(100)$ \\
\hline
\end{tabular}

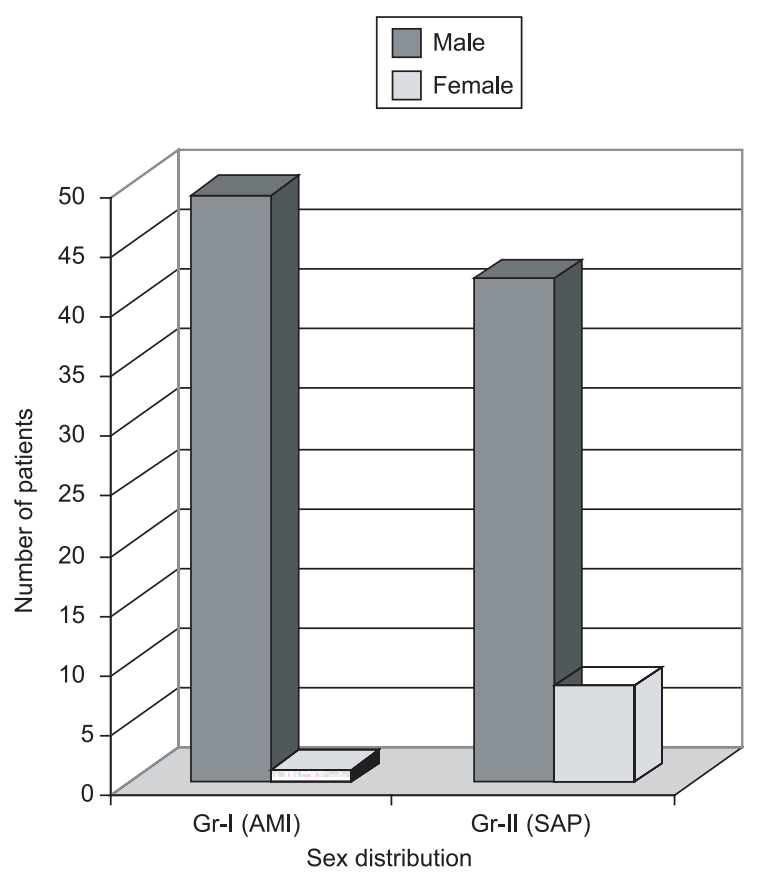

Fig-1: Sex distribution of study population $(N=100)$
Angiographically CAD ( $\geq 70 \%$ stenosis) were found in 93 patients and CAD were absent ( $<70 \%$ stenosis) in 7 cases. Among the positive cases single vessel disease(SVD), double vessel disease(DVD) and tripple vessel disease(TVD) were present in 31(31\%), 34(34\%) and 28(28\%) respectively. Regarding coronary vessels, LAD(left anterior descending) was involved in majority of patients(79 i.e,79\%), chronologically followed by RCA(right coronary artery) and LCx(left circumflex artery) system 48(48\%) and 34(34\%) respectively. A detail groupwise distribution and vessel involvement are shown in Table-II.

Table-II

Angiographic features of study population $(N=100)$

\begin{tabular}{|c|c|c|c|}
\hline $\begin{array}{l}\text { Variables } \\
\text { AM }\end{array}$ & $\begin{array}{l}\text { Gr-I } \\
\text { (Number) }\end{array}$ & $\begin{array}{c}\text { Gr-II } \\
\text { SAP (Number) }\end{array}$ & $\begin{array}{c}\text { Total } \\
\text { No (\%) }\end{array}$ \\
\hline \multicolumn{4}{|l|}{ ( $\geq 70 \%$ stenosis) } \\
\hline \multicolumn{3}{|l|}{ (<70\% stenosis) } & $7(7 \%)$ \\
\hline \multicolumn{4}{|c|}{ No. of diseased vessels } \\
\hline SVD & 27 & 4 & 31(31\%) \\
\hline DVD & 11 & 23 & $34(34 \%)$ \\
\hline TVD & 6 & 22 & $28(28 \%)$ \\
\hline LAD lesion & 32 & 47 & $79(79 \%)$ \\
\hline RCA lesion & 19 & 29 & $48(48 \%)$ \\
\hline LCx lesion & 16 & 18 & $34(34 \%)$ \\
\hline \multicolumn{2}{|c|}{ CAD- Coronary artery disease } & \multicolumn{2}{|c|}{$\begin{array}{l}\text { LAD-Left anterior } \\
\text { descending }\end{array}$} \\
\hline \multicolumn{2}{|c|}{ SVD-Single vessel disease } & \multicolumn{2}{|c|}{$\begin{array}{l}\text { RCA-Right coronary } \\
\text { artery }\end{array}$} \\
\hline \multicolumn{2}{|c|}{$\begin{array}{l}\text { DVD-Double vessel disease } \\
\text { TVD-Triple vessel disease }\end{array}$} & \multicolumn{2}{|c|}{ LCx-Left circumflex artery } \\
\hline
\end{tabular}

\section{Severity}

Severity of the disease was assessed in terms of number of diseased vessels, number of ( $370 \%)$ stenosis and number of total or subtotal oocclusion with TIMI score $<3$.

The angiograms of the two cohorts were evaluated and regarding number of vessels diseased, the AMI group had $1.52 \pm 0.68$ compared with $2.37 \pm 0.85$ vessels diseased (Fig-2) for the angina group reflecting significantly higher diseased vessel in latter group $(\mathrm{P}<0.001)$. The distribution of zero-, one-, two-, and three vessel disease were $12 \%$, $54 \%, 22 \%$, and $12 \%$ respectively in the infarction group; it was $2 \%, 8 \%, 46 \%$, and $44 \%$ respectively in the stable angina group(Fig-3). Thus from the above data it is clear that single vessel disease is more frequent in AMI group and double- and tripple vessel diseases are more prevalent in angina group. 


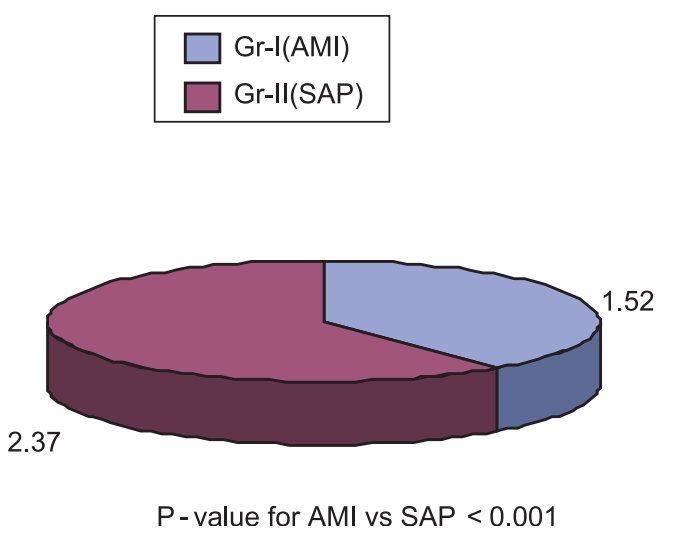

Fig-2: Comparison of mean diseased vessel number between the two groups $(N=100)$

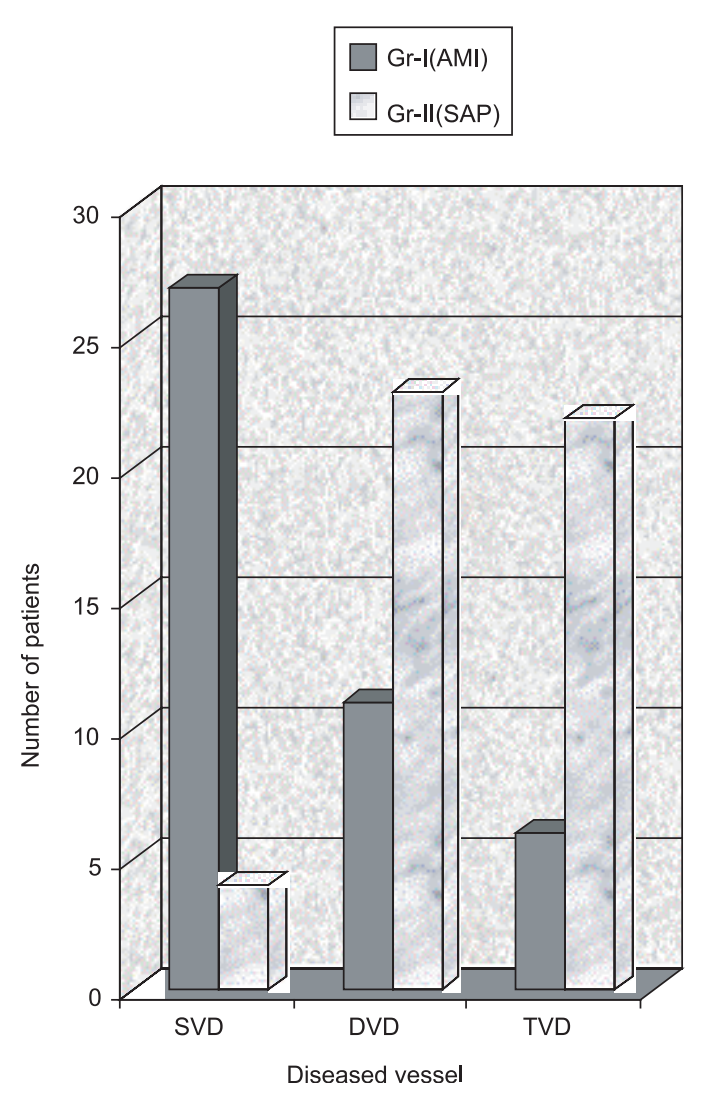

Fig-3: Distribution of diseased vessel among the two groups $(N=100)$

When the other two indexes of severity (stenoses and occlusions) were considered, the results were also similarly comparable to number of diseased vessels (TableVII and Table-VIII). In comparison with unheralded AMI, the stable angina group had greater number of stenoses $(4.16 \pm 1.9$ vs $2.14 \pm 1.5, \mathrm{P}<0.001)$ and also greater number of occlusions $(0.80 \pm 0.65$ vs $0.44 \pm 0.31, \mathrm{P}<0.001$ )(Table-3 and Fig-4).
Table-III

Comparison of number of stenosis( $\geq 50 \%$ narrowing) between two groups $(N=100)$.

\begin{tabular}{|c|c|c|c|}
\hline Diseased vessels & $\begin{array}{c}\text { Group-I } \\
(\mathrm{N}=50) \\
\text { Number of } \\
\text { stenosis } \\
(\mathrm{Mean} \pm \mathrm{SD})\end{array}$ & $\begin{array}{l}\text { Group-II } \\
(\mathrm{N}=50) \\
\text { Number of } \\
\text { stenosis } \\
(\text { Mean } \pm \mathrm{SD})\end{array}$ & $\mathrm{P}$ value \\
\hline Zero-vessel disease & $3(0.06 \pm 0.03)$ & $2(0.04 \pm 0.02)$ & NS \\
\hline Single-vessel disease & $37(0.74 \pm 0.28)$ & $11(0.22 \pm 0.08)$ & $<0.01$ \\
\hline Double-vessel disease & $36(0.72 \pm 0.30)$ & $91(1.82 \pm 0.65)$ & $<0.01$ \\
\hline Tripple-vessel disease & $31(0.62 \pm 0.25)$ & $104(2.08 \pm 0.71)$ & $<0.001$ \\
\hline Total & $107(2.14 \pm 1.50)$ & $208(4.16 \pm 1.90)$ & $<0.001$ \\
\hline
\end{tabular}

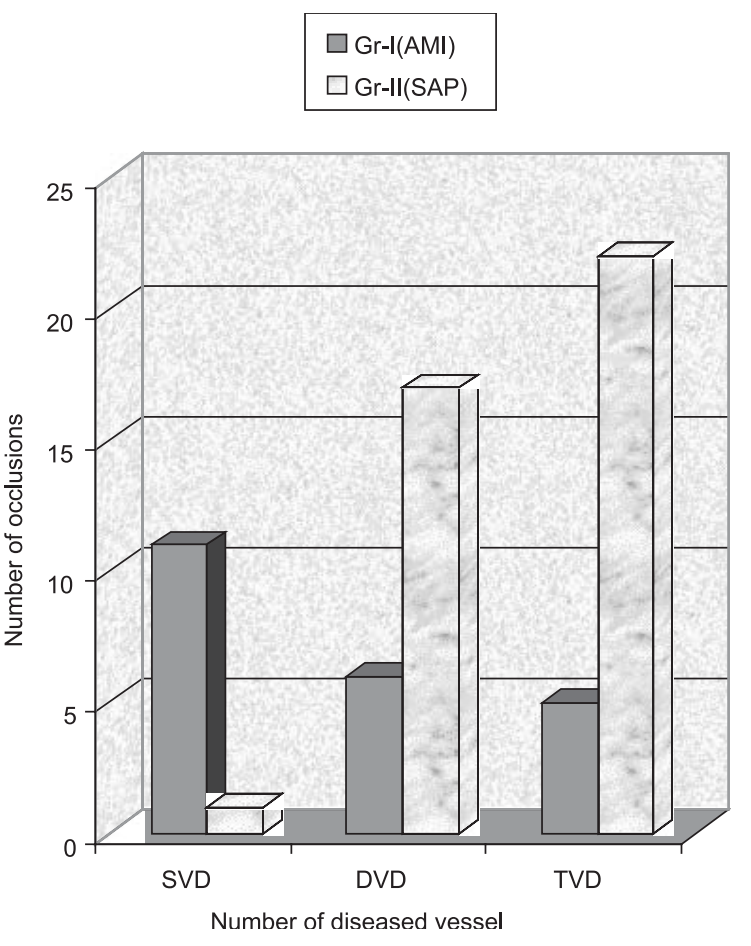

SVD- Single-vessel disease $\quad(\mathrm{P}<0.001)$

DVD- Double-vessel disease $(\mathrm{P}<0.01)$

TVD- Triple-vessel disease $\quad(\mathrm{P}<0.001)$

Fig-4: Comparison of number of occlusions/sub-total occlusions among the two groups of the study population $(N=100)$.

\section{Discussion}

\section{Baseline clinical characteristics}

This study observed markedly different angiographic appearence in patients with unheralded acute myocardial infarction undergoing coronary angiography compared with patients of stable angina pectoris. 
Amanullah et al in their 51-cases retrospective study of premature CAD found that unheralded AMI is much more commoner among the younger ${ }^{11}$.

Khandakar et al found that 18.74 percent of the acute myocardial infarction cases reporting to the hospital were below age 40 years and maximum incidence was in the age group 41-50years(32.30\%) $)^{12}$, which is comparable to the findings in presenting study showing in age group 3140years(32\%) and in 41-50 years(36\%), though here, only unheralded infarctions are included in AMI group.

Akanda et al demonstrated prevalence of single-, double, and tripple-vessel disease as 25\%, 33\%, and 42\% respectively among the CAD patients in general ${ }^{13}$, whereas the presenting study shows these as $31 \%$, 34\% and $28 \%$ respectively. This slight differences, particularly regarding tripple vessel diseases, might be due to highly selective grouping of study population in the presenting study.

\section{Severity of disease}

The major finding of this study is the markedly different angiographic appearence of unheralded acute myocardial infarction compared with stable angina pectoris. Whether the standard criterion of number of vessels diseased was used or the number of stenoses or occlusions or an index of disease extent, the results are concordant and discriminate clearly between the two groups. The angiograms of the two cohorts were evaluated and regarding number of vessels diseased, the AMI group had $1.52 \pm 0.68$ compared with $2.37 \pm 0.85$ vessels diseased (Fig-2) for the angina group reflecting significantly higher diseased vessel in latter group $(\mathrm{P}<0.001)$. The distribution of zero-, one-, two-, and three vessel disease were $12 \%$, $54 \%$, $22 \%$, and $12 \%$ respectively in the infarction group; it was $2 \%, 8 \%, 46 \%$, and $44 \%$ respectively in the stable angina group. Thus from the above data it is clear that single vessel disease is more frequent in AMI group and double- and tripple vessel diseases are more prevalent in angina group.

In comparison with unheralded AMI, the stable angina group had greater number of stenoses(4.16 \pm 1.9 vs $2.14 \pm 1.5$, $\mathrm{P}<0.001)$ and also greater number of occlusions $(0.80 \pm 0.65$ vs $0.44 \pm 0.31, \mathrm{P}<0.001)$. These finding correlates well with the previous similar studies done by Bogaty et al and Cianflone et al. ${ }^{9.10}$.

Besides in presenting study, the total number of lesions are also shown irrespective of their significance, including the minimal insignificant lesions. It shows significantly higher number of total lesions (273, mean
$5.46 \pm 1.13)$ in angina group than that of infarction group (155, mean 3.10 \pm 0.73 ), $\mathrm{P}<0.01$. In previous studies total lesions were not considered but from study of their extent index, the present findings seems to be similar and of significance.

Amanullah et al mentioned in their study that CAG of young MI patients demonstrated to have either normal CAG or focal lesions in one of the coronary arteries. ${ }^{11}$ The presenting study, in AMI group, also found similar results and thus correlates well.

\section{Study limitations}

Stringent clinical criteria were applied so that the 2 cohorts might constitute, as far as possible, pure subsets of coronary syndromes. Despite these precautions, the occurence of prior silent or inapparent acute coronary events cannot be excluded in the group of stable angina, nor can prior silent ischaemia in patients who presented with acute myocardial infarction . Another factor is the longer history of ischaemic heart disease in some patients with stable angina, which might have contributed to the greater severity and extent of coronary atherosclerosis. Even allowing for the interobserver differences, the simplified classification of patients with stable reversible myocardial ischaemia into single-, double-, and tripple-vessel disease is useful and widespread ${ }^{14.15}$. However data do exist to indicate that lesions of less than $50 \%$ narrowing also contribute to prognosis.

Normal coronary artery and coronary artery with insignificant lesion were found in both groups, comparatively more in AMI group in presenting study. There are only few exeptions in which despite the presence of ischemic chest pain, CAG findings are normal eg. syndrome $\mathrm{X}$, microvascular angina, coronary artery spasm and linked angina ${ }^{16-19}$. In these conditions atherosclerosis plays little role, if at all. Amanullah et al proposed these lesions as thrombogenic rather than atherogenic ${ }^{11}$. In AMI group it may be due to spontaneous lysis. Coronary thrombosis undergo spontaneous lysis, even if untreated, in about $50 \%$ of cases within 10 days $^{20}$. It is well established by coronary angiographic studies performed early in the course of an AMI that the infarct related artery is patent in $20 \%$ of patients, presumably reflecting spontaneous reperfusion .Moreover, there is a progressive increse in the percentage of arteries that are patent from 6 to 24 hours to 4 weeks, reflecting an increse in spontaneous thrombolysis over time ${ }^{2.20}$. 


\section{Summary and Conclusion}

The main objectives of the study were to compare the coronary angiographic severity between unheralded acute myocardial infarction and uncomplicated stable angina in Bangladeshi population

This study observed very significant difference in angiographic severity between two groups measured in terms of number of diseased vessels, number of stenoses and number of total or sub-total occlusions. This study correlated and observed significant differences in CAG findings between unheralded AMI and uncomplicated stable angina pectoris. There were fewer number of diseased vessels, fewer stenoses and discrete type of lesions in the former and more number of diseased vessels, more stenoses, and diffuse type of lesions in the latter.

As the study was done in highly selected group of patients, comprising small cohorts in one hospital only, the study may not reflect the true picture of Bangladeshi patients. But this study will definitely serve as a soil for similar future work in this field.

\section{References:}

1) Sones F.M, Shirey E.K: Cine coronary arteriography. Mod.Concepts Cardiovasc.Dis(AHA).1962; 31: 735-738.

2) Roberts R et al. Pathophysiology, Recognition, and treatment of Acute Myocardial Infarction and its Complications. In: Schlant RC and Alexander RW,editors. $8^{\text {th }}$ ed. The Heart. Philadelphia:McGrawhill Inc;1994:1108-1184.

3) Taeymans Y, Theroux P, Lesperance J, Waters D. Quantitative angiographic morphology of the coronary artery lesions at risk of thrombotic occlusion. Circulation 1992;85:78-85.

4) Buja LM and Willerson JT: Clinicopathologic correlates of acute ischaemic heart disease syndromes. Am J Cardiol 1981; 47: 343-356.

5) Betriu A , Castaner A, Sanz GA et al: Angiographic finding 1 month after myocardial infarction : A prospective study of 259 survivors. Circulation 1982; 65: 1099-1105.

6) Gersh BJ, Braunwald E, Rutherford JD. Chronic Coronary Artery Disease. In: Braunwald E, editor. Heart disease-A text book of cardiovascular medicine. $5^{\text {th }}$ ed. Philadelphia: W.B.Saunders company; 1997:1289-1365.

7) Abraham RD, Roubin GS, Harris PJ, Bernstein L and Kelly DT. Coronary and left ventricular angiographic anatomy and prognosis of survivors of first acute myocardial infarction.Am J Cardiol 1983;52:257-260.
8) Hackett D, Verwilghen J, Davies G, Maseri A. Coronary stenoses before and after acute myocardial infarction. Am J Cardiol 1989; 63: 1517-1518.

9) Bogaty P, Brecker SJ, White SE,Stevenson RN, Tamimi HEL, Balcon R, et al. Comparison of coronary angiographic findings in acute and chronic first presentation of ischaemic heart disease.Circulation 1993 ; 87: 1938-1946.

10) Cianflone D, Ciccirillo F, Buffon A, Trani C, ScabbiaEV, Finocchiaro ML,et al. Comparison of coronary angiographic narrowing in stable Angina pectoris, Unstable Angina Pectoris, and in Acute Myocardial infarction. Am $J$ Cardiol 1995;76:215-219.

11) Amanullah M, Thapa LB, Farooque GM, Hasanat A, Mohibullah AKM, Malik A. A profile of 51 cases of acute myocardial infarction amongst young Bangladeshi. In: Proceedings of Bangladesh-Japan joint conference on cardiovascular disease. Dhaka: JICA;1984:118-121.

12) Khandaker RK, Hossain D, Hossain M, Shamsuzzaman. Retrospective analysis of acute myocardial infarction : A four years study of 2690 patients. Bangladesh Ht Journal. 1986 ; $1: 14-17$.

13) Akanda MAK, Rahman S, Chowdhury AHK, Zaman S, Ali MA, Sadequzzaman M, et al. Arteriographic Pattern in Coronary Heart Disease in Bangladesh demonstrated by Selected Coronary Angiogram. Bangladesh Ht. Journal 1996;11:55-59.

14) Detre KM, Wright E, Murphy ML, Takaro T. Observer agreement in evaluating coronary angiograms. Circulation 1975; 52: 979-986.

15) Zir LM, Miller SW, Dinsmore RE, Gilbert JP, Harthorne JW. Interobserver variability in coronary arteriography. Circulation 1976; 53: 627-632.

16) Chaitman BR, Bourassa MG, Davis K, Rogers WJ, Tyras DH, Berger R,et al. Angiographic prevalence of high-risk coronary artery disease in patient subsets (CASS ). Circulation 1981 ; 64: 360-367.

17) Cannon RO III, Camici PG, Epstein SE: Pathophysiological dilemma of syndrome X.Circulation 1992; 85: 883-892.

18) Chauhan A, Mullins PA, Thuraisingham SI, Petch MC, Schofield PM. Clinical presentation and functional prognosis in syndrome X. Br Heart J 1993; 70: 346-351.

19) Holdright DR. Chest pain with normal coronary arteries. $\mathrm{Br} \mathrm{J}$ Hosp Med 1996; 56:347-350.

20) DeWood M, Spores J, Notske R, Mouser LT, Burroughs R, Golden MS, et al. Prevalence of total coronary occlusion during the early hours of transmural myocardial infarction. $N$ Engl J Med 1980; 303: 897-902. 